\title{
Expression of the Bumetanide-sensitive Na-K-Cl Cotransporter BSC2 Is Differentially Regulated by Fluid Mechanical and Inflammatory Cytokine Stimuli in Vascular Endothelium
}

\author{
James N. Topper, ${ }^{\ddagger}$ Scott M. Wasserman, ${ }^{\star}$ Keith R. Anderson, ${ }^{\star}$ Jiexing Cai, ${ }^{\S}$ Dean Falb, ${ }^{\S}$ and Michael A. Gimbrone, Jr. ${ }^{\star}$ \\ *Vascular Research Division, Department of Pathology, and ${ }^{\ddagger}$ Cardiovascular Division, Department of Medicine, Brigham and Women’s \\ Hospital and Harvard Medical School, Boston, Massachusetts 02115-5817; and ${ }^{\S}$ Millennium Pharmaceuticals, Cambridge, Massachusetts \\ $02139-4815$
}

\begin{abstract}
In vascular endothelium, the electroneutral $\mathrm{Na}-\mathrm{K}-\mathrm{Cl}$ cotransport system is thought to function in the maintenance of a selective permeability barrier in certain vascular beds (e.g., brain), as well as in the preservation of endothelial homeostasis in the face of fluctuating osmotic conditions that may accompany certain pathophysiological conditions (e.g., diabetes mellitus). Here we demonstrate that the gene encoding the bumetanide-sensitive cotransporter BSC2, one of the two major isoforms of $\mathrm{Na}-\mathrm{K}-\mathrm{Cl}$ cotransporters present in mammalian cells, can be differentially regulated by inflammatory cytokines and fluid mechanical forces in cultured endothelium. Interleukin-1 $\beta$ and tumor necrosis factor- $\alpha$ significantly upregulate expression of BSC 2 mRNA and protein in human umbilical vein endothelial cells, a response that is inhibited by pretreatment with interferon- $\gamma$. Steady laminar fluid shear stress, at a physiologic magnitude $\left(10 \mathrm{dyn} / \mathrm{cm}^{2}\right)$, is also able to induce and maintain elevated expression of BSC2 in cultured human umbilical vein endothelial cells, while a comparable time-averaged magnitude of turbulent fluid shear stress is not. In vivo, BSC2 mRNA is upregulated after intraperitoneal administration of bacterial endotoxin (LPS) in murine lung and kidney, but not in cardiac tissue. These results provide the first experimental evidence that the $\mathrm{BSC} 2$ gene can be selectively regulated by different inflammatory cytokine and fluid mechanical stimuli in endothelium, and support a role for BSC2 in vascular homeostasis and inflammation. (J. Clin. Invest. 1997. 99:2941-2949.) Key words: Na-K-Cl cotransport • endothelium • cytokines $\bullet$ shear stress $\bullet$ inflammation
\end{abstract}

\section{Introduction}

Most mammalian cells express a cell surface membrane-associated electroneutral $\mathrm{Na}-\mathrm{K}-\mathrm{Cl}$ cotransport system. In general, this system is thought to support two primary physiologic functions: vectorial transport of ions across certain polarized epithelia, and a more generalized regulation of intracellular vol-

Address correspondence to Michael A. Gimbrone, Jr., M.D., Vascular Research Division, Department of Pathology, Brigham and Women's Hospital, 221 Longwood Ave., LMRC 401, Boston, MA 02115-5817. Phone: 617-732-5901; FAX: 617-732-5933; E-mail: gimbrone@bust off.bwh.harvard.edu

Received for publication 22 November 1996 and accepted in revised form 20 March 1997.

J. Clin. Invest.

(C) The American Society for Clinical Investigation, Inc.

0021-9738/97/06/2941/09 \$2.00

Volume 99, Number 12, June 1997, 2941-2949 ume common to many cell types $(1,2)$. Specifically, in vascular endothelium, this system is thought to contribute to the maintenance of a selective permeability barrier at the blood-tissue interface in certain organs (e.g., the "blood-brain" barrier in the central nervous system), as well as the integrity of the vascular lining in response to fluctuations in ambient osmotic conditions that may accompany certain pathophysiologic states (e.g., diabetes mellitus) $(3,4)$. Because of the potential importance of electroneutral $\mathrm{Na}-\mathrm{K}-\mathrm{Cl}$ transport in the adaptation of endothelium (and other cell types) to varying physiologic and pathophysiologic conditions, the regulation of this class of transporters has been an active area of study. In addition, this system is the primary molecular target of a commonly used class of drugs known as the loop diuretics (hence the term bumetanide-sensitive $\mathrm{Na}-\mathrm{K}-\mathrm{Cl}$ transport), and thus the regulation (or dysregulation) of its expression may be relevant in a number of clinical disease settings.

Several laboratories have reported that the activity of this $\mathrm{Na}-\mathrm{K}-\mathrm{Cl}$ cotransport system is responsive to biochemical stimuli, such as vasoactive hormones, or biophysical stimuli, such as osmotic stresses, in both endothelial and nonendothelial cell types (3-5). This regulation of activity appears to occur predominantly at a posttranslational level as a result of the ability of cells to alter the activity of existing transport molecules via changes in their phosphorylation states $(1,6,7)$. Recently, the molecular basis for mammalian Na-K-Cl cotransport has begun to be elucidated via the identification of two genes encoding distinct electroneutral $\mathrm{Na}-\mathrm{K}-\mathrm{Cl}$ cotransport molecules (2, 8-12). The first gene, bumetanide-sensitive cotransporter 1 (BSC1, also known as NKCC2), ${ }^{1}$ encodes a kidney-specific $\mathrm{Na}-\mathrm{K}-\mathrm{Cl}$ cotransporter expressed on the apical surface of epithelial cells lining the thick ascending limb of Henle $(9,13,14)$. This molecule, also termed the absorptive form, is thought to play a central role in transcellular reabsorbtion of $\mathrm{NaCl}$ in the kidney tubule. A second gene, BSC2 (or NKCC1), encodes a more widely expressed cotransporter. This molecule (also known as the secretory form) is thought to function in intracellular volume regulation in a variety of cell types, as well as more specialized functions such as salt and water secretion across respiratory, sweat gland, and salivary epithelia $(1,8,15)$. Both of these molecules are members of the large superfamily of 12 membrane-spanning transporters whose members subserve diverse functions ranging from the transport of inorganic and organic ions to the regulation of macrophage activation and antimicrobial activity $(1,16)$.

1. Abbreviations used in this paper: BSC1, bumetanide-sensitive cotransporter 1; HUVEC, human umbilical vein endothelial cell; ICAM-1, intercellular adhesion molecule-1; LSS, laminar shear stress; rhIL-1 $\beta$, recombinant human IL-1 $\beta$; RT-PCR, reverse transcriptase-PCR; TSS, turbulent shear stress. 
In this report, we demonstrate that the levels of BSC2 mRNA and protein are selectively regulated by certain inflammatory cytokine and fluid mechanical stimuli in cultured human endothelial cells. Furthermore, systemic activation of endothelium and other cells by intraperitoneal Gram-negative bacterial endotoxin (LPS) administration in the mouse results in upregulation of this molecule in lung and kidney. These results demonstrate for the first time that the genes encoding the human and mouse $\mathrm{Na}-\mathrm{K}-\mathrm{Cl}$ cotransporter BSC2 can be regulated by both humoral and biomechanical stimuli, pointing to a more complex role for this molecule in vascular homeostasis than previously appreciated.

\section{Methods}

Endothelial cell culture. Human umbilical vein endothelial cells (HUVEC) were isolated from multiple segments of normal term umbilical cords, pooled and cultured in Medium 199 supplemented with Endothelial Cell Growth Supplement $(50 \mu \mathrm{g} / \mathrm{ml}$; Collaborative Research Inc., New Bedford, MA), heparin $(50 \mu \mathrm{g} / \mathrm{ml}$, porcine intestinal; Sigma Chemical Co., St. Louis, MO), antibiotics (100 U/ml penicillin-G, $100 \mu \mathrm{g} / \mathrm{ml}$ streptomycin; Sigma Chemical Co.), and $20 \%$ fetal bovine serum. Cells at passage level 2 or 3 (unless otherwise specified) were replicate plated on $0.1 \%$ gelatin-coated standard petri dishes or specially designed plates fabricated from the same tissue culture plastic (Costar Corp., Cambridge, MA), and allowed to grow to confluent densities before experimental use. For the experiments involving progressive passage of HUVEC (see Fig. $1 C$ ), a split ratio of 1:4 was employed at each subculture.

Differential display and semiquantitative reverse transcriptasePCR analyses. Differential display was performed on RNA isolated from HUVEC exposed to steady laminar and turbulent shear stresses, or the cytokine stimulus recombinant human IL-1 (rhIL-1 $\beta$ ), as previously described $(17,18)$. Semiquantitative reverse transcriptase (RT)-PCR were carried out as previously described (18). The sequences of the primers used for the RT-PCR analyses of BSC2 are as follows: BSC2, 5'GCAGTCCTTGTTCCTATGGC3' and 5'CACTAGGGATGCTAATGC3'; GAPDH, 5'TGAAGGTCGGTGTGAACGGATTTGGC3' and 5'CATGTAGGCCATGAGGTCCACCAC3'.

Cytokine treatment and Northern blot analysis. HUVEC at confluent densities were treated with cytokines by replacing the growth medium with identical medium supplemented with the appropriate cytokine. Recombinant human IL-1 $\beta$ (Biogen, Inc., Cambridge, MA) was used at 10-20 U/ml, TNF- $\alpha$ (Genzyme, Corp., Boston, MA) at $200 \mathrm{U} / \mathrm{ml}$, and interferon- $\gamma$ (Genzyme, Corp.) at 500-1,500 U/ml. Controls were treated identically without the addition of cytokine. RNA was isolated by guanidinium/phenol extraction, resolved on $1.2 \%$ agarose/formaldehyde gels, and transferred to nylon membranes by capillary blot. The probe for BSC2 consisted of a cDNA fragment generated by PCR corresponding to nucleotides 1850-2148 of the human BSC2 gene (accession No. U30246; Genbank/EMBL/DDBJ); this fragment possesses $<60 \%$ homology with the BSC1 gene. Blots were washed with $0.2 \times \mathrm{SSPE}$ and $0.1 \%$ SDS at $60^{\circ} \mathrm{C}$ and, after stripping, were reprobed with a cDNA encoding human GAPDH as a control for RNA loading.

Shear stress apparatus. Confluent HUVEC monolayers grown on 17.8-cm diameter "maxiplates" $\left(\sim 10^{7}\right.$ cells/plate $)$ were introduced into a coneplate flow cuvette (19) consisting of a stainless steel cone rotating over a stationary baseplate. The culture medium present between the cone and the plate was constantly replenished at the rate of 0.5 $\mathrm{ml} / \mathrm{min}$ during experiments, and the entire apparatus was maintained in a humidified $5 \% \mathrm{CO}_{2} / 95 \%$ air atmosphere. The equations and calculations for describing the shear stresses generated in this coneplate apparatus have been reported in detail previously (20). For laminar shear stress at $10 \mathrm{dyn} / \mathrm{cm}^{2}$, we used a $0.5^{\circ}$ cone at a rotational velocity of $100 \mathrm{rpm}$; for 4 or $12 \mathrm{dyn} / \mathrm{cm}^{2}$, the rotational velocity of the cone was
40 or 120 RPM, respectively. As described by Sdougos et al. (20), the parameter $\widetilde{R}$ is a function of the local radius from the center of the cone, the angular velocity of the cone, the angle of the cone itself, and the fluid kinematic viscosity of the media, and at values $<1$, it predicts laminar flow conditions. Turbulent shear stresses can be generated by manipulating these variables to achieve $\widetilde{R}$ values $>4$. Using a $3.0^{\circ}$ cone angle, a rotational velocity of $135 \mathrm{rpm}$ and radii $\geq 3.5 \mathrm{~cm}$, the $\widetilde{R}$ values are $>5$, and turbulence is predicted as well as observed experimentally. For the experiments involving pretreatment with interferon- $\gamma$, the cells were preincubated for $12 \mathrm{~h}$ in media containing IFN- $\gamma(500 \mathrm{U} / \mathrm{ml})$, and then exposed to laminar fluid shear stress (LSS) at $10 \mathrm{dyn} / \mathrm{cm}^{2}$ for $6 \mathrm{~h}$ in the continued presence of the cytokine.

Nuclear runoff analysis. Three maxiplates $\left(\sim 10^{7}\right.$ cells/plate $)$ were simultaneously prepared as above. One served as a control, one was treated with $20 \mathrm{U} / \mathrm{ml}$ of rhIL- $1 \beta$ for $3 \mathrm{~h}$, and the third was subjected to $3 \mathrm{~h}$ of steady LSS at $10 \mathrm{dyn} / \mathrm{cm}^{2}$ as above. Transcriptional rate of BSC2, intercellular adhesion molecule-1 (ICAM-1), and tubulin was assayed by nuclear runoff as described (18). Rsv-CAT is a plasmid that contains no endothelial genes and serves as a negative control.

Fluorescence immunoassay and indirect immunofluorescence. For the BSC2 immunoassay, HUVEC monolayers were prepared on specially constructed, tissue culture-treated plastic coverslips (Costar Corp.) and exposed to the appropriate stimuli. These were fixed and permeabilized with cold methanol $\left(-20^{\circ} \mathrm{C}\right)$ for $5 \mathrm{~min}$ and incubated with the primary antibody consisting of an affinity purified polyclonal rabbit antiserum directed against the carboxy (intracellular) terminus of the murine BSC2 molecule expressed as a fusion protein (kindly provided by E. Delpire, Children's Hospital, Boston, MA). This antisera is specific for the BSC2 isoform and does not cross-react with the BSC1 molecule (15). The monolayers were then washed and incubated with goat anti-rabbit IgG conjugated to FITC. After a second round of washing to reduce nonspecific binding, the monolayers were lysed in $0.01 \% \mathrm{NaOH}$ and $0.1 \%$ SDS and the fluorescence intensity was measured in a fluorimeter. Fold induction was calculated by dividing the fluorescence intensity of the test monolayers by the fluorescence of identical control monolayers that had not been exposed to the respective stimuli. For immunofluorescence microscopy, the monolayers were fixed and permeabilized as above and stained with the same primary antisera followed by a biotinylated goat anti-rabbit secondary antibody, detected with avidin-Texas red (Vector Laboratories, Inc., Burlingame, CA) and imaged with a Microphot-FXA fluorescence microscope (Nikon Inc., Melville, NY), and photographed with Ektachrome P1600 film (Eastman Kodak Co., Rochester, NY). To detect cell surface BSC2, HUVEC monolayers (static, rhIL-1 $\beta$ treated) were surface biotinylated with $0.5 \mathrm{mg} / \mathrm{ml}$ sulfo-NHS-biotin (Pierce, Rockford, IL) in Dulbecco's PBS. The cells were subsequently washed, lysed in $1 \%$ Triton X-100, $0.1 \mathrm{M}$ Tris- $\mathrm{HCl}, \mathrm{pH} 7.4$, $0.15 \mathrm{M} \mathrm{NaCl}, 5 \mathrm{mM}$ EDTA, $1 \mathrm{mM}$ PMSF, $10 \mu \mathrm{g} / \mathrm{ml}$ leupeptin, $60 \mathrm{U} /$ $\mathrm{ml}$ aprotinin, and immunoprecipitated with the anti-BSC2 antisera, or rabbit IgG as a control. The immunoprecipitates were run on $10 \%$ acrylamide gels, transferred to nitrocellulose, and probed with Streptavidin-HRP (Amersham Corp., Arlington Heights, IL), followed by a chemiluminescent substrate to detect biotinylated protein.

Induction of BSC2 expression in vivo. Young adult (6-8-wk old) C57/B6 mice were injected intraperitoneally with either sterile phosphate-buffered saline, $\mathrm{pH} 7.4$ (control), or $2 \mu \mathrm{g} / \mathrm{g}$ body wt purified Gram-negative bacterial endotoxin (LPS) (Sigma Chemical Co.). The mice were killed 24 or $48 \mathrm{~h}$ later, and the heart, lungs, and kidneys were harvested. For RNA analysis, the organs were homogenized in a polytron homogenizer, RNA isolated by guanidinium/phenol extraction, and Northern analysis was carried out as above.

\section{Results}

Identification of the cotransporter BSC2 as a regulated gene in cultured human endothelial cells. As part of an analysis aimed at identifying and characterizing novel genes regulated by both 


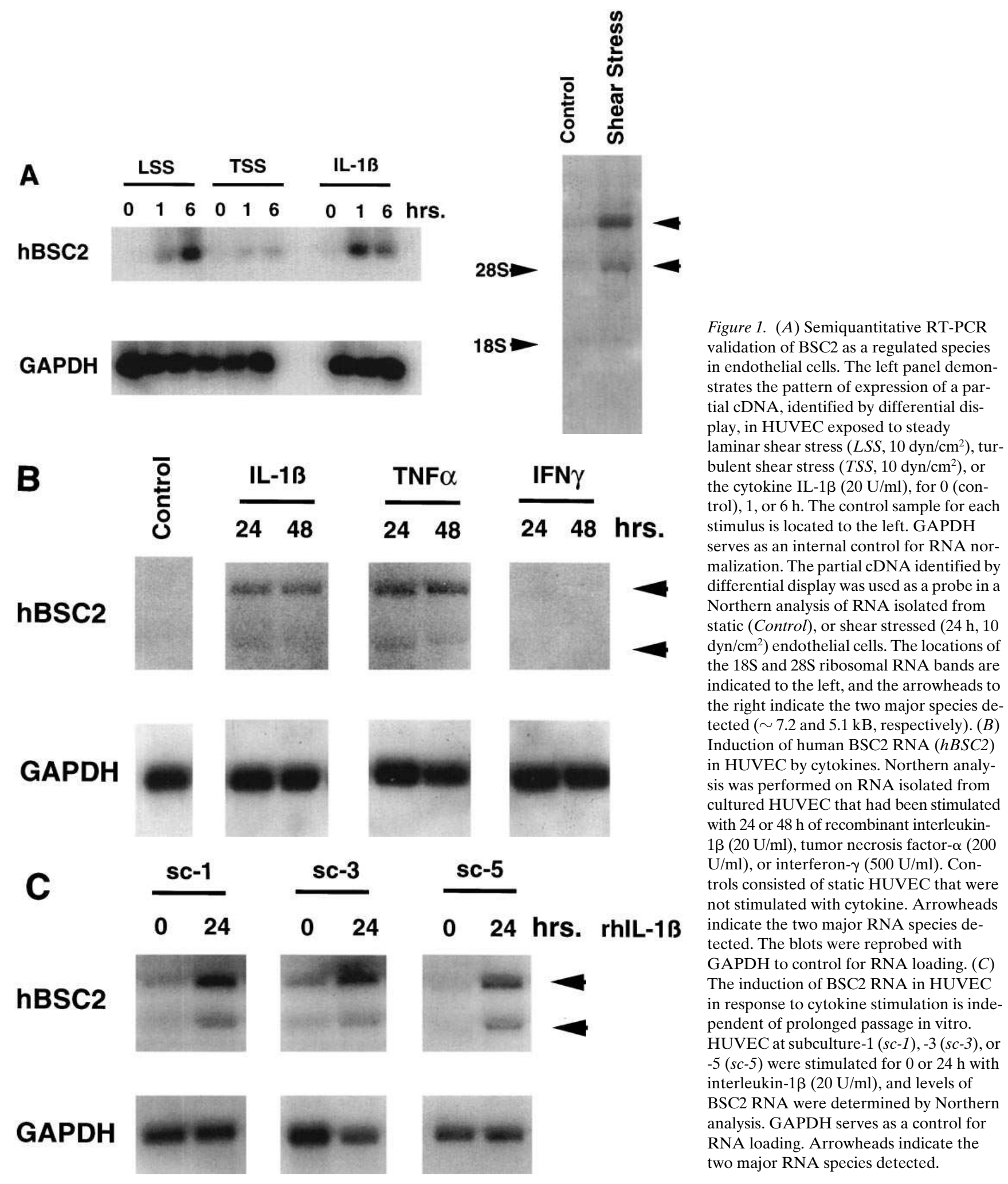

humoral and biomechanical stimuli in vascular endothelium, we exposed cultured HUVEC to three distinct types of stimuli and analyzed the resulting patterns of gene expression by differential display. The stimuli chosen consisted of a steady LSS at a physiologic magnitude $\left(10 \mathrm{dyn} / \mathrm{cm}^{2}\right)$, turbulent shear stress (TSS), a nonlaminar fluid mechanical stimulus of an equivalent time-averaged magnitude, and the soluble cytokine stimu- lus rhIL-1 $\beta$ at a maximally effective concentration $(20 \mathrm{U} / \mathrm{ml})$. As reported previously, these three distinct stimuli reproducibly elicit complex patterns of gene expression in these cells (18). One pattern, which we have termed "selective cytokine and laminar shear upregulation," was manifest by several transcripts identified by differential display, one of which is shown in Fig. $1 A$. As demonstrated by semiquantitative RT-PCR, a 
species labeled here as BSC2 (see below) is markedly upregulated by $6 \mathrm{~h}$ of steady LSS, but not by an equivalent exposure to TSS, and is also upregulated by the IL- $1 \beta$ cytokine stimulus. As shown in Fig. $1 A$, right, when the partial cDNA identified by differential display was cloned and used to probe RNA isolated from static and shear-stressed HUVEC, it identified two RNA species ( $\sim 7.2$ and $5.1 \mathrm{~kb}$ in length) that were upregulated significantly by exposure to steady laminar fluid shear stress. This partial cDNA was then sequenced and used to obtain a full length cDNA from a library constructed from cultured HUVEC. Initial sequence analysis revealed a novel member of the 12 membrane-spanning superfamily of transporters that was $\sim 70 \%$ homologous to a Na-K-Cl cotransporter from shark rectal gland (data not shown) (12). Subsequently, Payne et al. (11) reported the primary structure of the bumetanide-sensitive Na-K-Cl transporter (BSC2, NKCC1) from a human colonic cell line, and examination of that sequence revealed it to be identical to that of the human endothelial-derived clone.

The size of the larger transcript detected in Fig. $1 A$ is consistent with the reported size of the major transcript for the human BSC2 gene (11). In addition, we reproducibly observed a smaller, less abundant transcript of $\sim 5 \mathrm{~kb}$. Payne et al. have reported a transcript of this size in human kidney, which they identify as $\mathrm{BSC} 1$, or the kidney-specific isoform that is encoded by a separate gene (9-11). However, because the probe we used would not be predicted to hybridize to BSC1 RNA under the conditions employed (see Methods), this smaller transcript observed in HUVEC likely represents an alternative transcript generated from the BSC2 gene. This would be consistent with the results reported for the murine BSC2 gene, which has been demonstrated to produce two major transcripts similar in size to the two transcripts we detect in HUVEC, the longer consisting of a $3^{\prime}$ extension of the smaller transcript (8). The significance of these two alternative forms is currently unknown and, in all of our analyses, they appear to be coordinately regulated.

BSC2 gene is selectively responsive to certain inflammatory cytokines in vascular endothelium. To characterize the observed cytokine responsiveness of $\mathrm{BSC} 2$ in more detail, cultured HUVEC were exposed to rhIL-1 $\beta$, TNF- $\alpha$, and interferon- $\gamma$. As demonstrated in Fig. $1 B$ by Northern analysis, the steady state level of transcript for BSC2 was upregulated after 24 and $48 \mathrm{~h}$ of exposure to either rhIL-1 $\beta$ or TNF- $\alpha$. In contrast, interferon- $\gamma$ had no effect when added alone. Induction by rhIL-1 $\beta$ or TNF- $\alpha$ was seen as early as $3 \mathrm{~h}$ after exposure to the cytokine and appeared to peak at between 12 and $24 \mathrm{~h}$ (data not shown), and was sustained for at least $48 \mathrm{~h}$ (Fig. $1 B$ ). To address the issue of whether the significant inducibility demonstrated here related to serial passage in vitro (21), we tested the ability of isolated HUVEC at subculture 1, 3, or 5 to manifest induction of the BSC2 gene in response to IL-1 $\beta$. As seen in Fig. $1 C$, the cytokine inducibility of this gene was not significantly affected by serial passaging of the cells in vitro. Furthermore, rhIL-1 $\beta$ reproducibly induced significant upregulation of BSC2 in $>15$ separate HUVEC isolates that were tested (data not shown).

Interferon- $\gamma$ is an immunomodulatory molecule known to have diverse actions (22). In cultured HUVEC, it is capable of acting synergistically with the inflammatory cytokines IL-1 $\beta$ and $\mathrm{TNF}-\alpha$ to augment induction of certain cell surface adhesion molecules (23). In preliminary experiments designed to

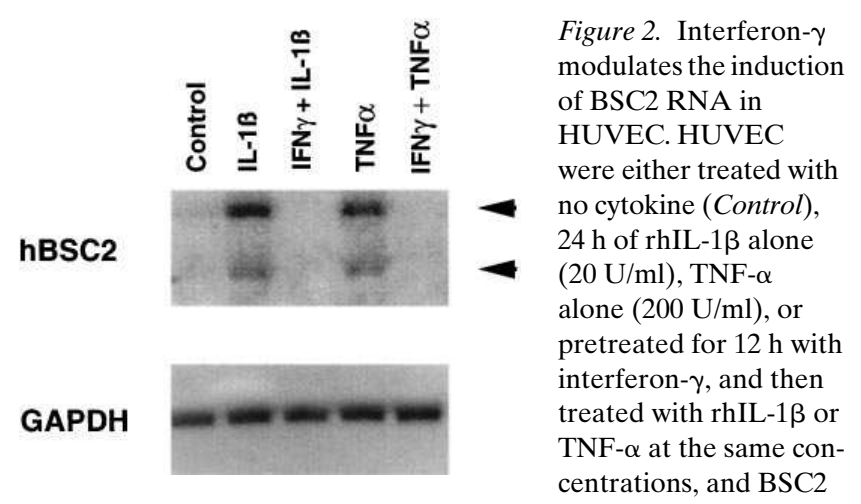

RNA was quantitated by Northern analysis. GAPDH serves as a control for RNA loading.

determine whether a similar effect would be seen with BSC2 gene regulation in HUVEC, we observed that the co-addition of interferon- $\gamma$ significantly blunted the response of this gene to both IL-1 $\beta$ and TNF- $\alpha$ (data not shown). To examine this further, HUVEC were preincubated with interferon- $\gamma$ for $12 \mathrm{~h}$, and then stimulated with IL- $1 \beta$ or TNF- $\alpha$ in the continued presence of interferon- $\gamma$. As demonstrated in Fig. 2, this resulted in almost complete inhibition of induction by either of these cytokines.

Differential regulation of BSC2 by fluid shear stress stimuli. A diverse group of genes has now been demonstrated to be regulated by fluid shear stress in vitro; however, to our knowledge BSC2 represents the first molecule of its class to be identified as a shear-responsive species (24-26). To further characterize this novel finding, we investigated the behavior of the BSC2 gene in response to a variety of shear stress conditions in vitro, using a coneplate flow apparatus as described in Methods. As demonstrated in the first two lanes of Fig. 3, $24 \mathrm{~h}$ of steady laminar shear stress at a magnitude of $10 \mathrm{dyn} / \mathrm{cm}^{2}$ results in a significant upregulation of the level of BSC2 mRNA. This level of induction is comparable with that observed after $24 \mathrm{~h}$ exposure to rhIL-1 $\beta$ (Fig. $3 A$, lane 4 ), while $24 \mathrm{~h}$ of turbulent shear stress, delivered at a comparable time-averaged magnitude, did not significantly induce this gene (Fig. $3 \mathrm{~A}$, lane 3 ). We performed a series of preconditioning experiments to further investigate this selective induction in response to steady laminar shear stress. As demonstrated in Fig. $3 A$, lanes 5-7, a lower magnitude of steady laminar shear stress (4 dyn/ $\mathrm{cm}^{2}$ ) for $24 \mathrm{~h}$ did not induce significant expression of BSC2 (Fig. $3 A$, lanes 5 and 6). However, when the cells were preconditioned by exposure for $18 \mathrm{~h}$ to this "lower" magnitude of laminar shear $\left(4 \mathrm{dyn} / \mathrm{cm}^{2}\right)$, and then exposed for only $6 \mathrm{~h}$ to a higher level of LSS (12 dyn/ $\left.\mathrm{cm}^{2}\right)$, significant induction of BSC2 was observed (Fig. $3 A$, lane 7 ). Interestingly, as shown in Fig. $3 A$, lanes 8 and 9 , the reciprocal experiment, consisting of preconditioning by exposure for $18 \mathrm{~h}$ to $12 \mathrm{dyn} / \mathrm{cm}^{2}$ of LSS, and then lowering the magnitude of applied shear stress to $4 \mathrm{dyn} /$ $\mathrm{cm}^{2}$ for an additional $6 \mathrm{~h}$, resulted in rapid decay in the level of BSC2 mRNA. These results suggest that the induction of BSC2 gene expression is dependent on both the nature and the magnitude of the applied fluid mechanical stimulus, and that sustained exposure to steady laminar shear stress, at a threshold level between 4 and $10 \mathrm{dyn} / \mathrm{cm}^{2}$, is necessary to maintain induction of the BSC2 gene in vitro.

To determine if IFN- $\gamma$ was capable of inhibiting the induc- 


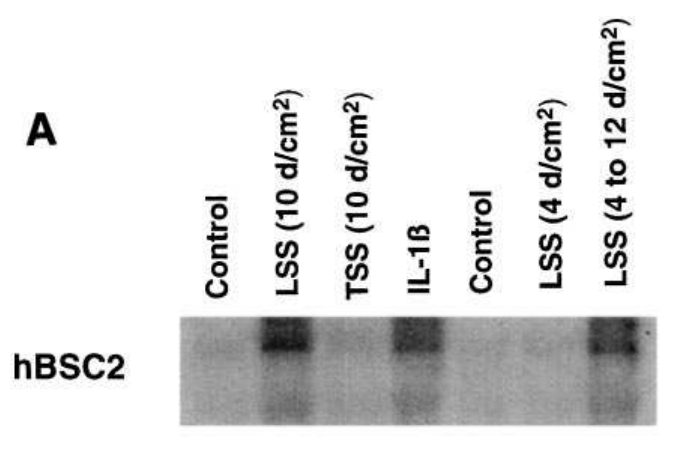

GAPDH

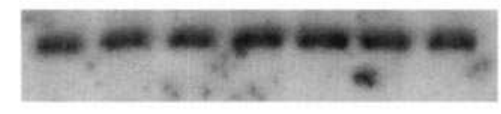

Lanes
1

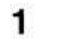

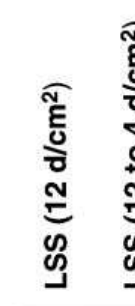
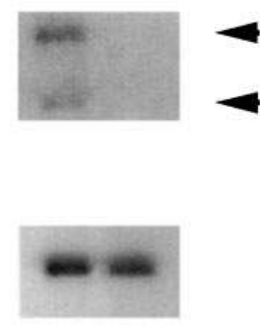

89
B

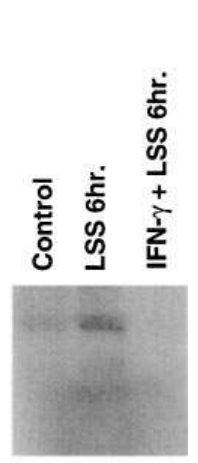

Figure 3. (A) BSC2 RNA is upregulated by fluid mechanical forces in HUVEC. (Lanes 1-4) Northern analysis of HUVEC exposed to static, no flow conditions (Control), or $24 \mathrm{~h}$ of steady laminar shear stress at $10 \mathrm{dyn} / \mathrm{cm}^{2}$ (LSS $\left.\left(10 \mathrm{~d} / \mathrm{cm}^{2}\right)\right)$, turbulent shear stress at the same time-averaged magnitude $\left(T S S\left(10 \mathrm{~d} / \mathrm{cm}^{2}\right)\right)$, or $20 \mathrm{U} /$ $\mathrm{ml}$ of rhIL-1 $\beta$. (Lanes 5-7) HUVEC were exposed to either static conditions (Control) or $24 \mathrm{~h}$ of steady laminar shear stress at $4 \mathrm{dyn} / \mathrm{cm}^{2}$ (LSS $\left.\left(4 \mathrm{~d} / \mathrm{cm}^{2}\right)\right)$, or $18 \mathrm{~h}$ of

steady laminar shear stress at $4 \mathrm{dyn} / \mathrm{cm}^{2}$, followed by $6 \mathrm{~h}$ of laminar shear stress at $12 \mathrm{dyn} / \mathrm{cm}^{2}$ ( LSS (4 to $\left.12 \mathrm{~d} / \mathrm{cm}^{2}\right)$ ). (Lanes 8 and 9 ) HUVEC were exposed to $24 \mathrm{~h}$ of steady laminar shear stress at $12 \mathrm{dyn} / \mathrm{cm}^{2}\left(\operatorname{LSS}\left(12 \mathrm{~d} / \mathrm{cm}^{2}\right)\right)$, or $18 \mathrm{~h}$ of steady laminar shear at $12 \mathrm{dyn} / \mathrm{cm}^{2}$ followed by $6 \mathrm{~h}$ of steady laminar shear at $4 \mathrm{dyn} / \mathrm{cm}^{2}\left(\operatorname{LSS}\left(12\right.\right.$ to $\left.\left.4 \mathrm{~d} / \mathrm{cm}^{2}\right)\right)$. (B) Interferon- $\gamma$ inhibits LSS-mediated induction of BSC2. HUVEC monolayers were subjected to static conditions (Control), LSS at $10 \mathrm{dyn} / \mathrm{cm}^{2}$ for $6 \mathrm{~h}$, or pretreatment with IFN- $\gamma(500 \mathrm{U} / \mathrm{ml})$ for $12 \mathrm{~h}$ followed by LSS at $10 \mathrm{dyn} /$ $\mathrm{cm}^{2}$ for $6 \mathrm{~h}$ in the presence of IFN- $\gamma$.

tion of the BSC2 gene in response to LSS, HUVEC were pretreated for $12 \mathrm{~h}$ with IFN- $\gamma(500 \mathrm{U} / \mathrm{ml})$, and then subjected to $6 \mathrm{~h}$ of LSS at $10 \mathrm{dyn} / \mathrm{cm}^{2}$ in the continued presence of IFN- $\gamma$. As demonstrated in Fig. $3 \mathrm{~B}, 6 \mathrm{~h}$ of LSS results in a significant induction of BSC2 mRNA, a response that is completely inhibited by the IFN- $\gamma$ treatment.

Upregulation of the BSC2 gene occurs at the level of transcriptional activation and results in increased expression of the BSC2 protein. To further investigate the mechanism of induction of the BSC2 gene in response to both cytokine and fluid
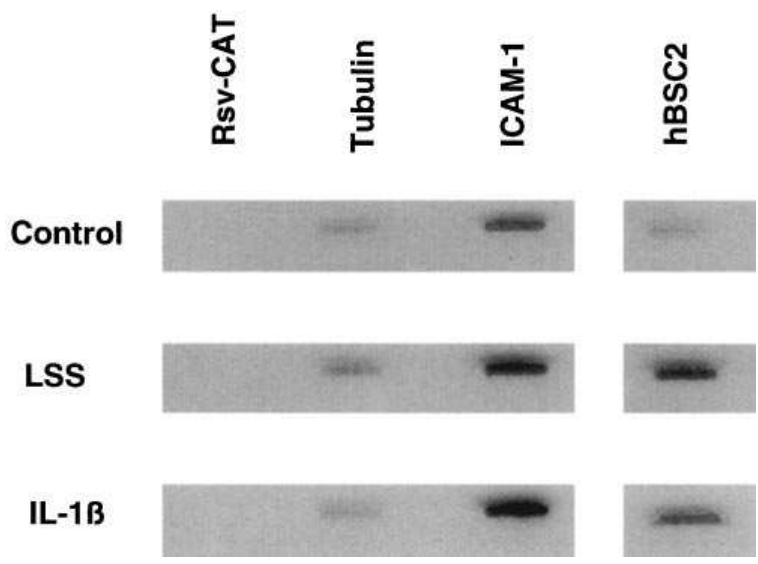

Figure 4. Nuclear runoff analysis of BSC2 in HUVEC exposed to IL$1 \beta$ or steady laminar shear stress $(L S S)$. HUVEC were exposed to $3 \mathrm{~h}$ of either rhIL-1 $\beta(20 \mathrm{U} / \mathrm{ml})$, steady laminar shear stress $\left(10 \mathrm{dyn} / \mathrm{cm}^{2}\right)$, or static conditions, and the transcriptional rates of the hBSC2, ICAM-1, and tubulin genes were measured by nuclear runoff as described in Methods. ICAM-1 is known to be upregulated by the cytokine and shear stress stimuli in HUVEC (18). Rsv-CAT is a plasmid containing no endothelial genes that serves as a control for the specificity of hybridization. mechanical stimuli, nuclear runoff analyses were performed. As demonstrated in Fig. 4, the transcriptional rate of the BSC2 gene was increased in cultured HUVEC in response to both LSS $\left(10 \mathrm{dyn} / \mathrm{cm}^{2}\right)$ and cytokine (rhIL-1 $\beta$ ) stimuli. The tubulin gene was not significantly affected by these stimuli, while the ICAM-1 gene also demonstrated transcriptional upregulation in response to both cytokine and shear stress stimuli, consistent with previous data (18). These results indicate that the upregulation of steady state mRNA for BSC2 occurs, at least in part, at the level of transcriptional activation, and suggest that one or more cis-acting elements within the promoter of this gene are responsive to shear stress and cytokine stimuli.

To determine whether this upregulation at the level of mRNA results in an increase in BSC2 protein, fluorescence immunoassays were performed using an affinity purified polyclonal antisera generated against the BSC2 protein (15). This polyclonal antibody is specific for the $\mathrm{BSC} 2$ isoform and crossreacts with the human molecule as evidenced by immunoblotting (data not shown). As seen in Fig. 5 A, total cellular immunoreactive BSC2 protein, quantified by immunobinding in permeabilized HUVEC monolayers, was increased approximately five- and eightfold, respectively, by exposure to steady laminar shear stress or rhIL-1 $\beta$. In addition, Fig. 6 illustrates immunofluorescence staining for BSC2 protein in HUVEC monolayers exposed to $24 \mathrm{~h}$ of laminar shear stress or rhIL-1 $\beta$ stimulation. As seen in Fig. $6 a$, $A$, static HUVEC demonstrate little, if any, specific immunofluorescence. In contrast, after a 24-h exposure to $10 \mathrm{dyn} / \mathrm{cm}^{2}$ of steady laminar shear stress, endothelial cells manifested a characteristic shape change and alignment in the direction of flow as well as a dramatic increase in BSC2 immunofluorescence (Fig. $6 a, B$ ). In response to the cytokine stimulus (rhIL-1 $\beta$ ), the level of immunofluorescence was also significantly increased, although without the typical morphological changes noted in the cells exposed to shear stress (Fig. 6 $a, C)$. Because the antisera used recognizes an intracellular epitope of BSC2 (and thus requires permeabilization of the 


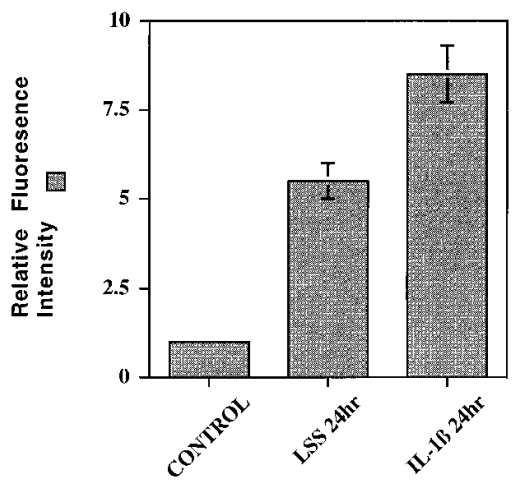

Figure 5. BSC2 protein is increased in HUVEC stimulated with laminar shear stress or rhIL-1 $\beta$. HUVEC monolayers subjected to static (CONTROL), $24 \mathrm{~h}$ of $10 \mathrm{dyn} / \mathrm{cm}^{2}$ laminar shear stress (LSS 24hr), or $24 \mathrm{~h}$ of $20 \mathrm{U} / \mathrm{ml} \mathrm{rhIL-}$ $1 \beta(I L-1 \beta 24 h r)$ were fixed, permeabilized, and the level of BSC2 protein was assayed by quantitative fluores-

cence immunoassay, using a specific polyclonal antisera as described in Methods. Average fold induction of fluorescence intensity relative to static control monolayers is presented for three separate experiments (error bars represent mean $\pm 1 \mathrm{SD}$ ).

cells), we employed surface labeling of HUVEC proteins to determine if increased amounts of $\mathrm{BSC} 2$ protein were present at the cell surface after BSC2 gene induction. As demonstrated by Western blotting in Fig. $6 b$, a significant increase in surface-biotinylated BSC2 protein is present after rhIL-1 $1 \beta$ treatment (compared with static controls), indicating that cytokine induction of the $\mathrm{BSC} 2$ gene results in increased $\mathrm{BSC} 2$ protein at the cell surface.

The level of BSC2 $m R N A$ is regulated in the lung and kidney in response to inflammatory stimuli in vivo. To investigate whether BSC2 could be regulated by inflammatory stimuli in vivo, we exposed mice to a systemic activation stimulus consisting of intraperitoneal Gram-negative bacterial endotoxin (LPS) administration. This proinflammatory stimulus induces the expression of a variety of endogenous cytokines, and also results in the induction of cytokine-regulated molecules in the vascular endothelium of many tissues in vivo (27). Fig. 7 is a Northern analysis of tissue from mice that were killed after either control injection of sterile PBS, or 24 or $48 \mathrm{~h}$ after intraperitoneal administration of LPS. As shown in Fig. 7, the human $\mathrm{BSC} 2$ probe used recognizes one major transcript of $\sim 7.3 \mathrm{~kb}$ in murine tissues, as well as a minor band at $\sim 4.5 \mathrm{~kb}$. These results are consistent with those reported by Delpire et al. (8). As demonstrated in Fig. 7 however, the steady state level of murine BSC2 message was significantly upregulated $48 \mathrm{~h}$ after intraperitoneal LPS administration in both lung and kidney, while its level remained unchanged in heart. This induction appeared to peak at $\sim 24 \mathrm{~h}$ and was sustained for at least $48 \mathrm{~h}$ after LPS administration (Fig. 7).

\section{Discussion}

This report provides the first experimental evidence that a member of the superfamily of 12 membrane-spanning transporters, known as BSC2, can be differentially regulated at the level of gene expression by both inflammatory cytokines and biomechanical stimuli in human vascular endothelium. In cultured HUVEC, the BSC2 gene is upregulated selectively by certain cytokines (IL-1 $\beta$ and TNF- $\alpha$, but not interferon- $\gamma$ ), as well as certain fluid mechanical stimuli (steady LSS but not TSS), in a time-dependent manner, and this upregulation results in increased levels of BSC2 protein. Previous studies have

\section{a}
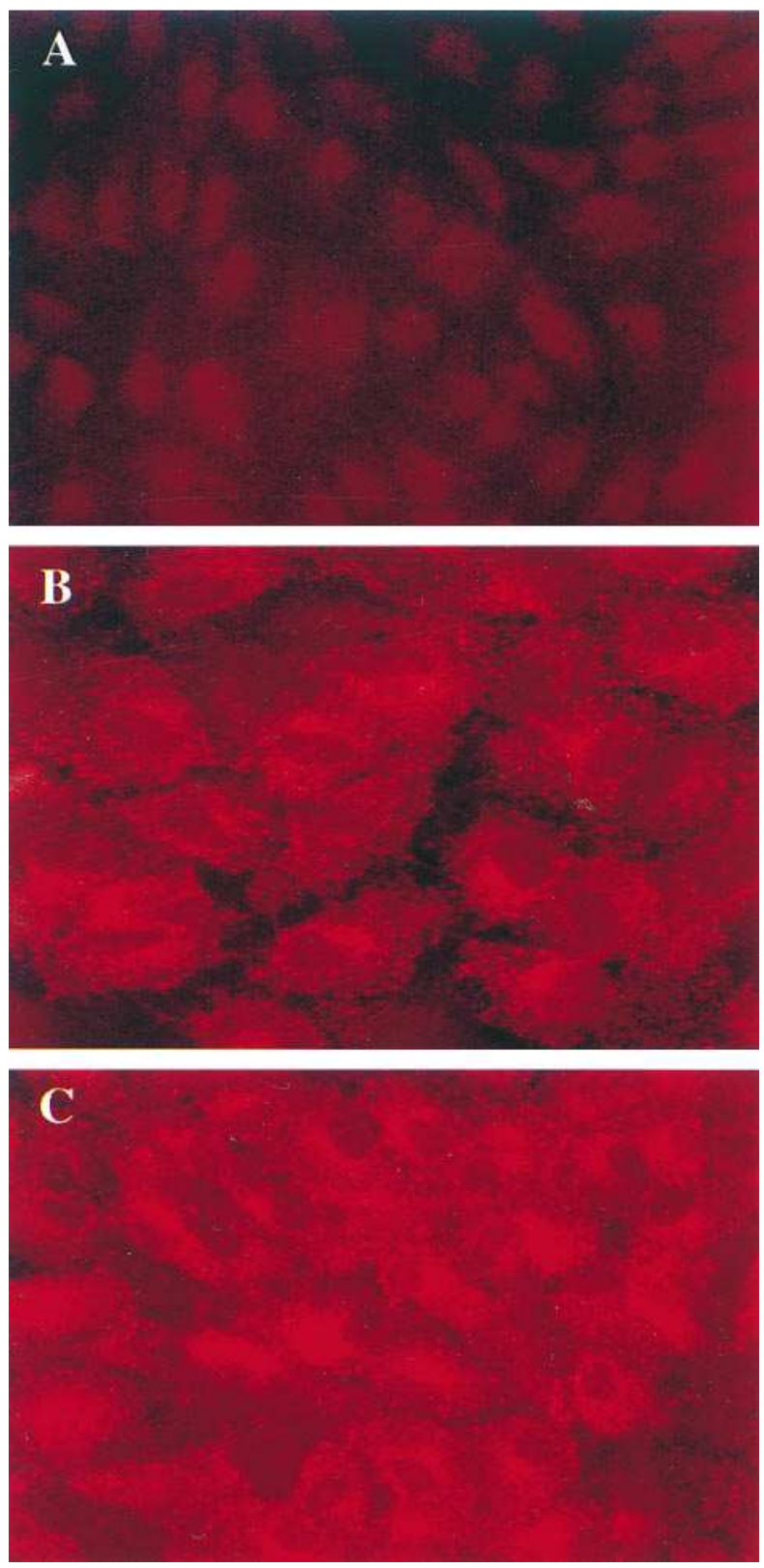

b Control rhIL-1B

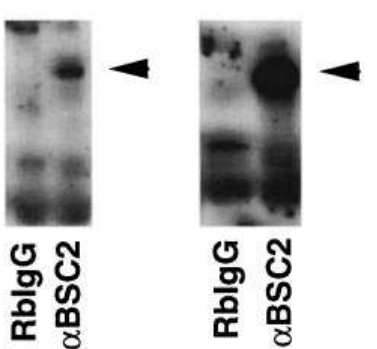

Figure 6. (a) Immunofluorescence microscopy of HUVEC monolayers subjected to shear stress or cytokine stimuli. HUVEC monolayers were exposed to static (control) conditions $(A), 24 \mathrm{~h}$ of laminar shear stress $(B)$ or $24 \mathrm{~h}$ of rhIL-1 $\beta$ $(C)$, as in Fig. 5. After fixation in methanol, specific staining with anti-BSC2 antisera was detected with Texas red, and images were obtained as described in Methods. The direction of fluid flow in $B$ was from left to right. (b) Cyto- kine-induced BSC2 protein is present at the cell surface. HUVEC monolayers were surface biotinylated (Methods), lysed, and protein was immunoprecipitated with anti-BSC2 antisera or rabbit IgG. Biotinyl-labeled proteins were detected by Western blotting with Streptavidin-HRP. The indicated bands thus represent cell surface BSC2 protein. 

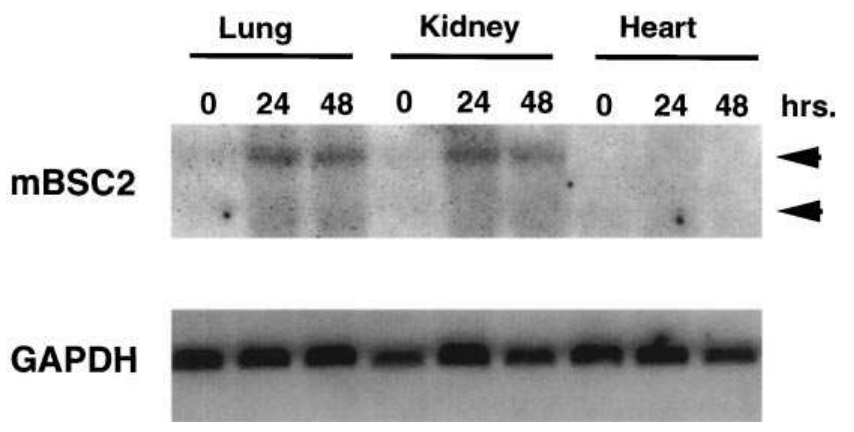

Figure 7. BSC2 RNA is upregulated in mouse lung and kidney after intraperitoneal LPS injection. Total RNA was isolated from mouse lung, kidney, and heart after intraperitoneal administration of sterile PBS as a control (0), or 24 and $48 \mathrm{~h}$ after administration of intraperitoneal Gram-negative bacterial endotoxin (LPS). The arrowheads to the right indicate the locations of the two transcripts detected in mouse tissues. GAPDH serves as a control for RNA loading.

shown that the activity of Na-K-Cl transporters can be significantly modulated by a variety of stimuli, in both endothelial and nonendothelial cell types, but, in most instances, this regulation appears to be occurring at the level of transporter protein activity $(1,6)$. For example, vasoactive substances such as angiotensin II, bradykinin, thrombin, and atrial naturietic protein, as well as growth factors such as nerve growth factor, can rapidly modulate the activity of existing transporter molecules via signaling pathways involving cyclic nucleotides and protein phosphorylation in vascular endothelium, smooth muscle, mesangial cells, and other cultured cell types (5-7, 28-30). Over longer time periods, certain stimuli also have been demonstrated to upregulate the number of transporter molecules. Examples of this type of upregulation include angiotensin IImediated induction in rat vascular smooth muscle and the induction of $\mathrm{Na}-\mathrm{K}-\mathrm{Cl}$ cotransport activity in bovine cerebral microvascular endothelial cells by coculture with astrocytes or their conditioned medium (31-33). In addition, arterial cells isolated from spontaneously hypertensive rats manifest reduced bumetanide-sensitive Na-K-Cl cotransport activity (34). However, the majority of the studies to date have involved quantitation of transporter activity via ion flux measurements or antagonist (bumetanide) binding to transporter molecules, and thus do not differentiate among the Na-K-Cl cotransporter isoforms involved, nor the level of their regulation (i.e., transcriptional versus posttranscriptional).

We found that the gene for BSC2 is induced $\sim 10-20$-fold at the mRNA level by both rhIL-1 $\beta$ and TNF- $\alpha$ in cultured endothelial cells, and that this increase in BSC2 message results in an 8-10-fold increase in BSC2 protein. This dramatic inducibility does not appear to be a consequence of prolonged passage of cells in vitro (21), since HUVEC at subculture-1 and -5 were comparably responsive to cytokine stimulation (Fig. $1 C$ ). In addition, cytokine-induced upregulation of $\mathrm{BSC} 2$ gene expression was not limited to cultured HUVEC, but was also observed with microvascular endothelial cells from murine lung, as well as macrovascular endothelial cells from bovine aorta, in response to TNF- $\alpha$ (J.N. Topper and S.M. Wasserman, unpublished observations). These observations provide a possible mechanism for the previously observed induction of BSC2 in bovine microvascular endothelium by coculture with brain as- trocytes that are capable of secreting inflammatory cytokines such as IL-1 $\beta(32,33)$. A similar paracrine (astrocyte-endothelial) regulatory loop has been demonstrated for other endothelial effector molecules and may have relevance to the modulation of blood-brain barrier function in vivo $(35,36)$.

The inhibition by interferon- $\gamma$ of the induction of BSC2 in response to IL- $1 \beta$ and TNF- $\alpha$ is an interesting feature of the cytokine modulation of this molecule in endothelial cells. Interferon- $\gamma$ is capable of inducing the expression of a variety of genes in endothelial and nonendothelial cell types (22). For example, interferon- $\gamma$ has been shown to increase expression of class II MHC molecules in cultured endothelial cells, and is capable of upregulating the vascular cell adhesion molecule-1 (VCAM-1) in rabbit smooth muscle cells $(23,37)$. In cultured HUVEC, interferon- $\gamma$ is capable of acting synergistically with IL-1 $\beta$ to augment expression of ICAM-1, an effect that is thought to involve posttranscriptional stabilization of ICAM-1 mRNA, while levels of E-selectin are not significantly affected (38). Thus, the ability of interferon- $\gamma$ to inhibit the induction of BSC2 is not a nonspecific cytotoxic effect, and these results suggest that the regulation of the inducible expression of BSC2 by inflammatory and immune cytokines may be a complex phenomenon. Interestingly, this pattern of interferon- $\gamma$-inhibitable cytokine responsiveness resembles that of the PDGF-A and -B genes in HUVEC (39). These genes are also induced by the inflammatory cytokines IL- $1 \beta$ and TNF- $\alpha$ in endothelium, a response that is significantly attenuated by concomitant treatment with interferon- $\gamma$.

In addition to demonstrating selective induction by certain cytokine stimuli in vitro, we have shown that BSC2 appears to be upregulated by systemic inflammatory activation in vivo. Administration of intraperitoneal LPS resulted in a significant upregulation of the steady state level of BSC2 mRNA in murine kidney and lung (Fig. 7). However, no significant upregulation of BSC2 mRNA was observed in the heart, another highly vascularized tissue, although significant upregulation of VCAM-1 protein in capillary endothelium (an index of endothelial activation) was detected in this tissue (data not shown). This selective pattern of induction of BSC2 mRNA suggests that expression of the BSC2 gene can be differentially regulated at the tissue level, perhaps reflecting tissue- or cellspecific factors yet to be defined. In a recent report (15), positive immunofluorescence staining of constitutively expressed BSC2 protein was confined to collecting duct epithelium, glomerulus, and afferent arteriole in the unstimulated murine kidney, while most vascular structures did not display significant amounts of BSC2. Current efforts are directed at defining the cellular distribution of inducible BSC2 protein in organs such as the lung and kidney after systemic inflammatory activation. Bacterial endotoxin stimulation is capable of directly activating endothelium and other tissues while also inducing a variety of secondary effects such as the elaboration of potent cytokines and vasoactive molecules by leukocytes. Both the elevated plasma levels of these mediators, as well as the hemodynamic alterations they can induce, may be mechanistically important in the induction of the $\mathrm{BSC} 2$ gene demonstrated here. Thus, although these results demonstrate that the BSC2 gene can be regulated in vivo, further work will be required to define the role of the specific humoral and/or biomechanical stimuli involved.

In addition to its cytokine responsiveness, we have also demonstrated that the $\mathrm{BSC} 2$ gene can be differentially regu- 
lated by fluid mechanical forces applied to cultured endothelial cells. Although fluid mechanical forces have been shown to regulate the expression of a wide variety of pathophysiologically important effectors in endothelium, BSC2 represents the first molecule of its class (a 12 membrane-spanning transporter) to demonstrate responsiveness to shear stress at the level of gene expression (24-26). This response appears selective in that sustained steady laminar shear stress at a physiologic magnitude of $10 \mathrm{dyn} / \mathrm{cm}^{2}$ is capable of inducing this gene, while a comparable time-averaged magnitude of turbulent shear stress (a definably nonlaminar fluid mechanical stimulus) (40) does not induce BSC2 expression. Furthermore, in addition to the nature of the fluid shear stress (laminar versus nonlaminar), the magnitude of the applied shear also appears to be important. Sustained exposure of HUVEC to a lower level of laminar shear stress $\left(4 \mathrm{dyn} / \mathrm{cm}^{2}\right)$ resulted in minimal induction of BSC2. This relatively low level of shear stress is capable of inducing a number of acute events in cultured endothelium, such as the stimulation of an inward rectifying potassium current, mobilization of intracellular calcium, and the flow-stimulated release of endothelium-derived relaxing factor, but is typically below the threshold needed to induce sustained morphological changes (e.g., cell shape change, cytoskeletal reorganization) in cultured endothelial cells $(24,25)$. When the cells are preconditioned under this low level of laminar shear $\left(4 \mathrm{dyn} / \mathrm{cm}^{2}\right)$, and then exposed to a higher level of steady laminar shear $\left(12 \mathrm{dyn} / \mathrm{cm}^{2}\right)$ for only $6 \mathrm{~h}$, the BSC2 gene is promptly induced, suggesting that the lower level of shear stress is not inhibitory per se, but rather represents an inadequate stimulus for induction of BSC2. When the BSC 2 gene is induced by $18 \mathrm{~h}$ of steady laminar shear stress at $12 \mathrm{dyn} / \mathrm{cm}^{2}$, and then the magnitude of applied shear stress is reduced to $4 \mathrm{dyn} / \mathrm{cm}^{2}$, the expression of BSC2 RNA quickly declines. These results suggest that it is not the acute transition from a static (no flow) state that is the relevant stimulus in vitro, but rather that a minimum or threshold level of sustained fluid shear stress (between 4 and $10 \mathrm{dyn} / \mathrm{cm}^{2}$ ) is required to maintain elevated expression of this gene in vitro, and that in the absence of this stimulus, the level of BSC2 RNA quickly decays.

The BSC2 gene is induced at the transcriptional level by both cytokine and fluid mechanical stimuli, as evidenced by nuclear runoff analysis (Fig. 4). Resnick et al. have demonstrated that the transient induction of the PDGF-B gene in response to steady laminar shear stress was dependent upon a cis-acting transcriptional element termed the "shear stress response element" (SSRE) (41). Subsequently, a number of genes have been demonstrated to be induced by fluid shear stress at the transcriptional level in endothelial cells, and several distinct transcriptional regulatory elements have been implicated in these responses $(42,43)$. The ability of IFN- $\gamma$ to interfere with both humoral (e.g., cytokine) and biomechanical (e.g., laminar fluid shear stress) stimulation of BSC2 gene expression in vitro suggests that common transduction mechanisms are involved in these responses. Analysis of the promoter of the BSC2 gene should yield interesting insights into transcriptional mechanisms involved in its differential regulation by diverse types of humoral and biomechanical stimuli.

In summary, we have demonstrated that the gene encoding the bumetanide-sensitive, electroneutral Na-K-Cl cotransporter (BSC2) is differentially regulated by certain inflammatory cytokines and fluid shear stresses in cultured endothelial cells. This gene can also be induced in vivo within the kidney and lung by intraperitoneal administration of bacterial endotoxin. These data identify BSC2 as an inducible gene, selectively responsive to humoral and biomechanical stimuli. The regulated expression of this molecule in endothelial cells may play an important role in vascular homeostasis in both health and disease.

\section{Acknowledgments}

We thank W. Atkinson and K. Case for endothelial cell culturing, T. Nagel and N. Resnick for assistance with the fluid mechanical systems, G. Stavrakis for assistance with antibody staining, and J. Kiely, T. Michel, and E. Delpire for helpful discussions.

J.N. Topper is a recipient of the Howard Hughes Medical Institute Postdoctoral Fellowship for Physicians. S.M. Wasserman is a recipient of the Howard Hughes Medical Institute Research Training Fellowship for Medical Students. This research was supported in part by grants to M.A. Gimbrone from the National Institutes of Health (R37-HL51150 and PO1-HL4874).

\section{References} C885

1. Haas, M. 1994. The Na-K-Cl cotransporters. Am. J. Physiol. 267:C869-

2. Hebert, S.C., and S.R. Gullans. 1995. The electroneutral sodium-(potassium)-chloride co-transporter family: a journey from fish to the renal co-transporters [editorial]. Curr. Opin. Nephrol. Hypertens. 4:389-391.

3. O'Donnell, M.E. 1989. $\left[{ }^{3} \mathrm{H}\right]$ Bumetanide binding in vascular endothelial cells. Quantitation of Na-K-Cl cotransporters. J. Biol. Chem. 264:20326-20330.

4. O'Donnell, M.E. 1993. Role of Na-K-Cl cotransport in vascular endothelial cell volume regulation. Am. J. Physiol. 264:C1316-C1326.

5. Vigne, P., A. Lopez Farre, and C. Frelin. 1994. $\mathrm{Na}(+)-\mathrm{K}(+)-\mathrm{Cl}-$ cotransporter of brain capillary endothelial cells. Properties and regulation by endothelins, hyperosmolar solutions, calyculin A, and interleukin-1. J. Biol. Chem. 269:19925-19930.

6. O’Donnell, M.E., A. Martinez, and D. Sun. 1995. Endothelial Na-K-Cl cotransport regulation by tonicity and hormones: phosphorylation of cotransport protein. Am. J. Physiol. 269:C1513-C1523.

7. Leung, S., M.E. O'Donnell, A. Martinez, and H.C. Palfrey. 1994. Regulation by nerve growth factor and protein phosphorylation of $\mathrm{Na} / \mathrm{K} / 2 \mathrm{Cl}$ cotransport and cell volume in PC12 cells. J. Biol. Chem. 269:10581-10589.

8. Delpire, E., M.I. Rauchman, D.R. Beier, S.C. Hebert, and S.R. Gullans. 1994. Molecular cloning and chromosome localization of a putative basolateral $\mathrm{Na}(+)-\mathrm{K}(+)$-2Cl- cotransporter from mouse inner medullary collecting duct (mIMCD-3) cells. J. Biol. Chem. 269:25677-25683.

9. Payne, J.A., and B.R. Forbush. 1994. Alternatively spliced isoforms of the putative renal Na-K-Cl cotransporter are differentially distributed within the rabbit kidney. Proc. Natl. Acad. Sci. USA. 91:4544-4548.

10. Payne, J.A., and B.R. Forbush. 1995. Molecular characterization of the epithelial Na-K-Cl cotransporter isoforms. Curr. Opin. Cell Biol. 7:493-503.

11. Payne, J.A., J.C. Xu, M. Haas, C.Y. Lytle, D. Ward, and B.R. Forbush 1995. Primary structure, functional expression, and chromosomal localization of the bumetanide-sensitive Na-K-Cl cotransporter in human colon. J. Biol. Chem. 270:17977-17985.

12. Xu, J.C., C. Lytle, T.T. Zhu, J.A. Payne, E. Benz, Jr., and B.R. Forbush. 1994. Molecular cloning and functional expression of the bumetanide-sensitive Na-K-Cl cotransporter. Proc. Natl. Acad. Sci. USA. 91:2201-2205.

13. Gamba, G., A. Miyanoshita, M. Lombardi, J. Lytton, W.S. Lee, M.A. Hediger, and S.C. Hebert. 1994. Molecular cloning, primary structure, and characterization of two members of the mammalian electroneutral sodium(potassium)-chloride cotransporter family expressed in kidney. J. Biol. Chem. 269:17713-17722.

14. Obermuller, N., S. Kunchaparty, D.H. Ellison, and S. Bachmann. 1996. Expression of the Na-K-2Cl cotransporter by macula densa and thick ascending limb cells of rat and rabbit nephron. J. Clin. Invest. 98:635-640.

15. Kaplan, M.R., M.D. Plotkin, D. Brown, S.C. Hebert, and E. Delpire. 1996. Expression of the mouse $\mathrm{Na}-\mathrm{K}-2 \mathrm{Cl}$ cotransporter, $\mathrm{mBSC} 2$, in the terminal inner medullary collecting duct, the glomerular and extraglomerular mesangium, and the glomerular afferent arteriole. J. Clin. Invest. 98:723-730.

16. Cellier, M., G. Prive, A. Belouchi, T. Kwan, V. Rodrigues, W. Chia, and P. Gros. 1995. Nramp defines a family of membrane proteins. Proc. Natl. Acad. Sci. USA. 92:10089-10093.

17. Liang, P., and A.B. Pardee. 1992. Differential display of eukaryotic messenger RNA by means of the polymerase chain reaction [see comments]. Science (Wash. DC). 257:967-971.

18. Topper, J.N., J. Cai, D. Falb, and M.A. Gimbrone, Jr. 1996. Identifica- 
tion of vascular endothelial genes differentially responsive to fluid mechanical stimuli: cyclooxygenase-2, manganese superoxide dismutase, and endothelial cell nitric oxide synthase are selectively up-regulated by steady laminar shear stress. Proc. Natl. Acad. Sci. USA. 93:10417-10422.

19. Bussolari, S.R., C.F. Dewey, Jr., and M.A. Gimbrone, Jr. 1982. Apparatus for subjecting living cells to fluid shear stress. Rev. Sci. Instrum. 53:18511854.

20. Sdougos, H.P., S.R. Bussolari, and C.F. Dewey. 1984. Secondary flow and turbulence in a cone-and-plate device. Journal of Fluid Mechanics. 138:379404.

21. Raat, N.J., E. Delpire, C.H. van Os, and R.J. Bindels. 1996. Culturing induced expression of basolateral $\mathrm{Na}+-\mathrm{K}+-2 \mathrm{Cl}-$ cotransporter $\mathrm{BSC} 2$ in proximal tubule, aortic endothelium, and vascular smooth muscle. Pflug. Arch. Eur. J. Physiol. 431:458-460.

22. Williams, B.R. 1991. Transcriptional regulation of interferon-stimulated genes. Eur. J. Biochem. 200:1-11.

23. Pober, J.S., and R.S. Cotran. 1990. Cytokines and endothelial cell biology. Physiol. Rev. 70:427-451.

24. Davies, P.F., and S.C. Tripathi. 1993. Mechanical stress mechanisms and the cell: an endothelial paradigm. Circ. Res. 72:239-245.

25. Davies, P.F. 1995. Flow-mediated endothelial mechanotransduction. Physiol. Rev. 75:519-560.

26. Resnick, N., and M.A. Gimbrone, Jr. 1995. Hemodynamic forces are complex regulators of endothelial gene expression. FASEB J. 9:874-882.

27. Fries, J.W., A.J. Williams, R.C. Atkins, W. Newman, M.F. Lipscomb, and T. Collins. 1993. Expression of VCAM-1 and E-selectin in an in vivo model of endothelial activation. Am. J. Pathol. 143:725-737.

28. Brock, T.A., C. Brugnara, M. Canessa, and M.A. Gimbrone, Jr. 1986. Bradykinin and vasopressin stimulate $\mathrm{Na}+-\mathrm{K}+-\mathrm{Cl}$ - cotransport in cultured endothelial cells. Am. J. Physiol. 250:C888-C895.

29. O'Donnell, M.E. 1989. Regulation of Na-K-Cl cotransport in endothelial cells by atrial natriuretic factor. Am. J. Physiol. 257:C36-C44.

30. Panet, R., and H. Atlan. 1991. Stimulation of bumetanide-sensitive $\mathrm{Na}+/ \mathrm{K}+/ \mathrm{Cl}$ - cotransport by different mitogens in synchronized human skin fibroblasts is essential for cell proliferation. J. Cell Biol. 114:337-342.

31. Tseng, H., and B.C. Berk. 1992. The $\mathrm{Na} / \mathrm{K} / 2 \mathrm{Cl}$ cotransporter is increased in hypertrophied vascular smooth muscle cells. J. Biol. Chem. 267: $8161-8167$

32. Sun, D., C. Lytle, and M.E. O’Donnell. 1995. Astroglial cell-induced expression of Na-K-Cl cotransporter in brain microvascular endothelial cells. Am.
J. Physiol. 269:C1506-C1512.

33. O'Donnell, M.E., A. Martinez, and D. Sun. 1995. Cerebral microvascular endothelial cell Na-K-Cl cotransport: regulation by astrocyte-conditioned medium. Am. J. Physiol. 268:C747-C754

34. O'Donnell, M.E., and N.E. Owen. 1988. Reduced Na-K-Cl cotransport in vascular smooth muscle cells from spontaneously hypertensive rats. Am. $J$. Physiol. 255:C169-C180.

35. DeBault, L.E., and P.A. Cancilla. 1980. gamma-Glutamyl transpeptidase in isolated brain endothelial cells: induction by glial cells in vitro. Science (Wash. DC). 207:653-655.

36. Maxwell, K., J.A. Berliner, and P.A. Cancilla. 1987. Induction of gamma-glutamyl transpeptidase in cultured cerebral endothelial cells by a product released by astrocytes. Brain Res. 410:309-314

37. Li, H., M.I. Cybulsky, M.A. Gimbrone, Jr., and P. Libby. 1993. Inducible expression of vascular cell adhesion molecule-1 by vascular smooth muscle cells in vitro and within rabbit atheroma. Am. J. Path. 143:1551-1559.

38. Ohh, M., C.A. Smith, C. Carpenito, and F. Takei. 1994. Regulation of intercellular adhesion molecule-1 gene expression involves multiple mRNA stabilization mechanisms: effects of interferon-gamma and phorbol myristate acetate. Blood. 84:2632-2639.

39. Suzuki, H. K. Shibano, M. Okane, I. Kono, Y. Matsui, K. Yamane, and H. Kashiwagi. 1989. Interferon-gamma modulates messenger RNA levels of c-sis (PDGF-B chain), PDGF-A chain, and IL-1 beta genes in human vascular endothelial cells. Am. J. Pathol. 134:35-43.

40. Davies, P.F., A. Remuzzi, E.J. Gordon, C.F. Dewey, Jr., and M.A. Gimbrone, Jr. 1986. Turbulent fluid shear stress induces vascular endothelial cell turnover in vitro. Proc. Natl. Acad. Sci. USA. 83:2114-2117.

41. Resnick, N., T. Collins, W. Atkinson, D.T. Bonthron, C.F.J. Dewey, and M.A.J. Gimbrone. 1993. Platelet-derived growth factor B chain promoter contains a cis-acting fluid shear-stress-responsive element [published erratum ap pears in Proc. Natl. Acad. Sci. USA. 1993. 90:7908]. Proc. Natl. Acad. Sci. USA. 90:4591-4595.

42. Ohno, M., J.P. Cooke, V.J. Dzau, and G.H. Gibbons. 1995. Fluid shear stress induces endothelial transforming growth factor beta-1 transcription and production. Modulation by potassium channel blockade. J. Clin. Invest. 95: 1363-1369.

43. Shyy, J.Y., M.C. Lin, J. Han, Y. Lu, M. Petrime, and S. Chien. 1995. The cis-acting phorbol ester "12-O-tetradecanoylphorbol 13-acetate"-responsive element is involved in shear stress-induced monocyte chemotactic protein 1 gene expression. Proc. Natl. Acad. Sci. USA. 92:8069-8073. 